\title{
Helminth community structure and diet of three Afrotropical anuran species: a test of the interactive-versus-isolationist parasite communities hypothesis
}

\author{
G. C. Akani ${ }^{1}$, L. Luiselli ${ }^{2}$, C. C. Amuzie ${ }^{1}$, and G. N. Wokem ${ }^{3}$ \\ ${ }^{1}$ Department of Applied and Environmental Biology, Rivers State University of Science \& Technology, \\ P.M.B. 5080, Port Harcourt, Nigeria \\ ${ }^{2}$ Institute of Environmental Studies Demetra, Via Olona 7, 00198, Rome, Italy \\ ${ }^{3}$ Department of Medical Laboratory Sciences, Rivers State University of Science \& Technology, \\ P.M.B. 5080, Port Harcourt, Nigeria
}

Received: 9 June 2011 - Revised: 9 July 2011 - Accepted: 14 July 2011 - Published: 6 September 2011

\begin{abstract}
The interactive-versus-isolationist hypothesis predicts that parasite communities should be depauperated and weakly structured by interspecific competition in amphibians. A parasitological survey was carried out to test this hypothesis using three anuran species from Nigeria, tropical Africa (one Bufonidae; two Ranidae). High values of parasite infection parameters were found in all three species, which were infected by nematodes, cestodes and trematodes. Nonetheless, the parasite communities of the three anurans were very depauperated in terms of number of species (4 to 6). Interspecific competition was irrelevant in all species, as revealed by null models and Monte Carlo permutations. Cluster analyses revealed that, in terms of parasite community composition, the two Ranidae were similar, whereas the Bufonidae was more different. However, when prevalence, intensity, and abundance of parasites are combined into a multivariate analysis, each anuran species was clearly spaced apart from the others, thus revealing considerable species-specific differences in terms of their parasite communities. All anurans were generalists and probably opportunistic in terms of dietary habits, and showed no evidence of interspecific competition for food. Overall, our data are widely consistent with expectations driven from the interactive-versus-isolationist parasite communities hypothesis.
\end{abstract}

\section{Introduction}

The most successful theoretical framework for parasite community ecology research has been the interactive versus isolationist classification of parasite communities (Holmes and Price, 1986; Esch et al., 1990; Sousa, 1994), now viewed as extremes of a continuum rather than a dichotomy given the huge variability observed in natural assemblages of parasites (Poulin, 2001; Poulin and Luque, 2003). According to this theoretical framework, interactive parasite communities consist of many species, most with high host colonization rates (Holmes and Price, 1986). These features result in infracommunities (Bush et al., 1997) with many co-occurring para-

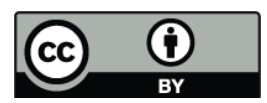

Correspondence to: L. Luiselli (lucamlu@tin.it) site species, several having large infrapopulation sizes, and thus niche overlap and interspecific interactions are potentially extensive (Poulin, 2001; Poulin and Luque, 2003). In contrast, isolationist communities consist of fewer species, most with limited colonisation abilities; their infrapopulations are generally small and only rarely co-occur with those of other species in the same host at intensities high enough to result in significant interactions (Holmes and Price, 1986; Poulin, 2001; Poulin and Luque, 2003). This dichotomy is certainly useful but still difficult to apply because (i) most parasite communities fall somewhere in-between these extremes, and (ii) when applied to real data, the classification of parasite communities along the continuum has been the matter of subjective judgment as there is no single measure of the general degree of interactivity in parasite communities (but see Poulin and Luque (2003) for the development of an index). 
Helminthes are important parasites of free-ranging amphibians (Baker, 1987; Bursey et al., 2001), with an ecological role in regulating amphibian population demography being still little studied (Baker, 1987; Aho, 1990; Anderson, 2000; McAllister et al., 2010). Typically, helminth communities of amphibians are species-poor assemblages where interactions are unlikely (Aho, 1990; Barton, 1999). Several factors have been advocated to explain the fact that amphibian helminth communities are depauperated (Aho, 1990) and belong to the isolationist extremity of the continuum, including a generalized opportunistic diet, simple intestinal system, low vagility and ectothermic metabolism of their hosts (Barton, 1999).

Most of the studies analyzing community structure of helminthes parasitizing amphibians were conducted in temperate regions (e.g., Bolek and Coggins, 2001; Muzzall et al., 2001; Brooks et al., 2006), whereas studies on tropical helminthes and their amphibian hosts are uncommon in the international literature, and mainly confined to Central and South American study systems (e.g., Bursey et al., 2001; Hamann et al., 2006). Studies on African tropical systems are even rarer, and concerning the helminth fauna of amphibians in Nigeria, there are just a few studies available to date (Anyacho, 1997; Anosike and Keke, 2002; Aisien et al., 2003). All these studies were simply descriptive. No study, however, analyzed the frog helminthes in a community ecology perspective (Friggens and Brown, 2005).

The lack of community ecology research on helminthes parasitizing anurans in African tropical regions is particularly unfortunate, not only in the light of the theoretical framework above-mentioned but also because many helminth species exploit food-web relationships, and are valuable as means of reflecting the biodiversity of their habitat (Marcogliese, 2001). Host feeding and diet are important in helminth acquisition, and the habitat from which the bulk of food is obtained is as important as the diet in parasite fauna acquisition (Guidelli et al., 2003).

In this paper, we analyze the helminth fauna and the diet parameters of three contrasted species of African tropical anurans: a terrestrial toad (Amietophrynus (= Bufo) maculatus; Bufonidae), a large-sized aquatic frog (Hoplobatrachus occipitalis; Ranidae), and a smaller sized aquatic frog (Ptychadena aequiplicata, Ranidae) from Port Harcourt, Nigeria. More specifically, we address the following key questions: (i) do helminth communities of the three anuran species mentioned above belong to the interactive versus isolationist side of the continuum? Our hypothesis is that they should belong to the isolationist side, as predicted from the majority of studies on amphibian parasites from elsewhere (Aho, 1990; Barton, 1999); (ii) are the helminth communities structured by interspecific competition? We hypothesize that interspecific competition should be irrelevant for these helminth communities, as suggested by previous amphibian studies (Aho, 1990; Barton, 1999); (iii) are the studied anuran species generalists in diets? We predict that they should be general- ist, because dietary generalism is one of the factors producing depauperated communities of parasites in these ectothermic vertebrates, at least for trematodes and cestodes (Barton, 1999). We explored these issues by using null models (Gotelli and Graves, 1996), with emphasis on determining whether the helminth communities are non-randomly structured within their anuran hosts, i.e. whether the location of the various helminth species within the host's gastrointestinal system may be determined by resource partitioning patterns (for the case of cestodes within elasmobranchs, see Friggens and Brown, 2005).

\section{Materials and methods}

\subsection{Study area}

We randomly collected amphibians from ponds, wet grasses and refuse dumps around residential areas of Port Harcourt (co-ordinates $04^{\circ} 45^{\prime} \mathrm{N}$; $07^{\circ} 01^{\prime} \mathrm{E}$; Rivers State), in the Niger Delta region of southern Nigeria. The study sites were precisely: Rumuokwu-

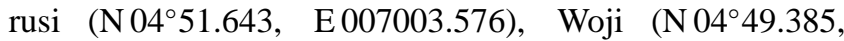
E 007003.710'), Azubie (N 0448.682' E 007003.112'), and Rumunduru ( $\mathrm{N}^{\circ} 52.239^{\prime}$ E 007001.806'). All collection sites were geographically close, so the data was pooled. We did not sample intensively a single area for conservation reasons, i.e. for avoiding removal of an excessive number of anuran individuals from a same population. The study area has relatively slight monthly fluctuations in maximum and minimum temperatures $\left(27-33^{\circ} \mathrm{C}\right)$, and high mean relative humidity of over $65 \%$ in most months of the year. The dry season extends from November to April and the wet season extends May to October, with peaks in July and September.

\subsection{Sampling protocol}

Overall, 116 specimens of Amietophrynus maculatus (69 males and 47 females), 9 specimens of Hoplobatrachus occipitalis (6 males and 3 females) and 15 specimens of Ptychadena aequiplicata ( 9 females and 6 males) were collected within short period (May to November 2008) in order to minimize the seasonal variations on enteric helminth infracommunity structure occurring in the hosts (Verma and Singh, 2000; Bolek and Coggins, 2001). We decided not to sacrify more individuals of the two latter species for conservation purposes, because they are widespread but usually not abundant in the studied ponds.

The specimens were transported alive to the laboratory where they were humanely sacrificed with MS 222, commercially available as Tricaine Methane Sulfonate (TMS). Tricaine is a benzoic acid derivative and, in water of low alkalinity ( $<50 \mathrm{mg} \mathrm{L}^{-1}$ as $\mathrm{CaCO}_{3}$ ), the solution was buffered with sodium bicarbonate. A $10 \mathrm{~g} \mathrm{~L}^{-1}$ stock solution was made, and sodium bicarbonate added to saturation, resulting in a $\mathrm{pH}$ between 7.0 and 7.5 for the solution (Anonymous, 2006). 
The body cavity was opened by longitudinal incision from throat to vent and the gut was detached by cutting across the esophagus and rectum (Goldberg and Bursey, 2007). Thereafter, it was severed into four regions: esophagus, stomach, intestine, and colon. Each segment was opened longitudinally and placed separately in a watch glass containing normal saline to extract the helminthes. They were preserved in vials containing $70 \%$ ethanol until later examination. $\mathrm{Ne}-$ matodes were identified after clearing in a drop of undiluted glycerol on a glass slide; cestodes and trematodes were regressively stained in haematoxylin, dehydrated in graded ethanol and mounted in balsam for examination (Goldberg and Bursey, 2007). The helminthes were subsequently identified to possible taxonomic level, using a high resolution compound microscope (Model: National Motic A07270). After counting, (i) prevalence was calculated as the percentage of infected individuals of each species; (ii) mean intensity as the number of helminthes per infected frog; and (iii) species-richness was the number of helminth species per frog (Verma and Singh, 2000). Voucher helminthes and frogs were deposited in the Museum, Department of Applied and Environmental Biology, Rivers State University of Science and Technology, Port Harcourt.

Food items of anuran individuals were also removed, identified and counted. With some exceptions, order level was used as the operational taxonomic unit (OTU, Sneath and Sokal, 1973) for identification. The use of descriptive ecological terms is according to Bush et al. (1997).

\subsection{Statistical analyses}

The following parameters were calculated: abundance (number of helminthes or prey items), richness (number of parasite species), diversity and evenness. Parametric tests were used after having verified data normality and homoscedasticity. Non-normal data were log-transformed to achieve normality, and then parametric tests were used. ANOVA was used to calculate differences between means in multiple population groups. Frequency differences in helminthes among the various segments of the gastrointestinal system of anurans were analyzed by observed versus expected $\chi^{2}$ test. UPGMA dendrogram (with Euclidean distances) were used to cluster dissimilarities between anurans in terms of their parasite species, and between parasites in terms of their occurrence among the three anuran species.

Helminth communities within each anuran species were analyzed for random/nonrandom organization patterns by null models (Gotelli and Graves, 1996), with each sector of the anuran gastrointestinal tract being considered a different microhabitat resource. The same approach was previously used by Friggens and Brown (2005) for cestode communities of elasmobranchs. To evaluate whether each helminth community was structured randomly or not, we contrasted the actual data matrix with 30000 random "pseudo-communities" generated by Monte Carlo simulations (Gotelli and Graves,
1996). Pianka's (1986) overlap formula was calculated for all communities, and the original species utilization matrices from which Pianka's overlap was calculated were randomized by shuffling the original values among the resource states. We used two randomization algorithms (RA2 and RA3) of Lawlor (1980), as they are particularly robust for niche overlap studies (Gotelli and Graves, 1996). RA2 tests for structure in the generalist-specialist nature of the resource utilization matrix by conserving guild structure, but destroying observed niche breadth (Gotelli and Graves, 1996; Luiselli, 2006, 2008). RA3 tests for guild structure by conserving niche breadth for each species, but destroying guild structure manifested by the zero structure of the resource utilization matrix (Gotelli and Graves, 1996; Luiselli, 2006, 2008). Niche overlap values were calculated for each of these randomly generated matrices, and species-pair and community-summary statistics were computed (Friggens and Brown, 2005). Actual overlap values were then compared to the distributions of the expected values. Structure was assumed when $P_{\text {obs } \leq \exp }<0.05$ (Gotelli and Graves, 1996). In all cases, equiprobable resource use was assumed. The same algorithm procedures and the same number of random Monte Carlo permutations were also performed to test niche partitioning patterns in food habits of the three sympatric anurans. We used the EcoSim software (Acquired Intelligence Corp., Kesey-Bear) to calculate overlap indices and to generate Monte Carlo simulations.

Apart from null models, all the other statistical tests were done according to Zar (1984) and Fowler and Cohen (1994), and performed by a Statistica for Windows (version 6.0) software.

\section{Results}

\subsection{General patterns of helminth distribution across anuran species and gastrointestinal tracts}

A total of 2903 helminthes were extracted from the anurans examined; 2495 (85.9\%) from Amietophrynus maculatus, $240(8.3 \%)$ from Hoplobatrachus occipitalis, while $168(5.8 \%)$ were from Ptychadena aequiplicata. In all, there were nine helminth species infecting the anurans; 3 nematodes, 3 trematodes, and 3 cestodes (Table 1), with the highest helminth burden record being due to the nematodes, Rhabdias bufonis and Oxyuris sp.

Six helminth species were recovered from Amietophrynus maculatus specimens, including nematodes, cestodes, and trematodes (two species each). Hoplobatrachus occipitalis harbored four helminth species, including 2 nematodes, 1 cestode, and 1 trematode. Five helminth species were recovered from Ptychadena aequiplicata, including 2 nematodes, 1 cestode, 1 trematode and 1 monogenean. Two helminthes (Oxyuris sp. and Eurytrema sp.) were found in all anurans, two in two anurans, and the rest were found in only an anuran species. 
Table 1. Summary of the numbers of helminthes extracted from different segments of the anuran guts in three species from Port Harcourt, Nigeria.

\begin{tabular}{|c|c|c|c|c|c|c|c|}
\hline Anura (Host) species & Helminth species & Phylum & Esophagus & Stomach & Intestine & Colon & Total \\
\hline \multicolumn{8}{|c|}{ Amietophrynus maculates } \\
\hline & Rhabdias bufonis & Nematoda & 12 & 357 & 782 & 28 & 1179 \\
\hline & Oxyuris sp. & Nematoda & 0 & 17 & 78 & 929 & 1024 \\
\hline & Eurytrema sp. & Trematoda & 0 & 119 & 108 & 32 & 259 \\
\hline & Mehraorchis sp. & Trematoda & 0 & 0 & 5 & 0 & 5 \\
\hline & Davainea sp. & Cestoda & 0 & 1 & 12 & 0 & 13 \\
\hline & Diphyllobothrium sp. & Cestoda & 0 & 0 & 15 & 0 & 15 \\
\hline \multicolumn{8}{|c|}{ Hoplobatrachus occipitalis } \\
\hline & Aplectana acuminata & Nematoda & 0 & 5 & 16 & 0 & 21 \\
\hline & Oxyuris sp. & Nematoda & 0 & 0 & 3 & 106 & 109 \\
\hline & Eurytrema sp. & Trematoda & 0 & 35 & 62 & 7 & 104 \\
\hline & Diphyllobothrium sp. & Cestoda & 0 & 0 & 6 & 0 & 6 \\
\hline \multicolumn{8}{|c|}{ Ptychadena aequiplicata } \\
\hline & Aplectana acuminata & Nematoda & 0 & 8 & 20 & 0 & 28 \\
\hline & Oxyuris sp. & Nematoda & 0 & 0 & 2 & 62 & 64 \\
\hline & Eurytrema sp. & Trematoda & 0 & 21 & 46 & 3 & 70 \\
\hline & Polystoma sp. & Monogenea & 0 & 0 & 1 & 0 & 1 \\
\hline & Raillietina sp. & Cestoda & 0 & 0 & 5 & 0 & 5 \\
\hline TOTAL & & & 12 & 563 & 1161 & 1167 & 2903 \\
\hline
\end{tabular}

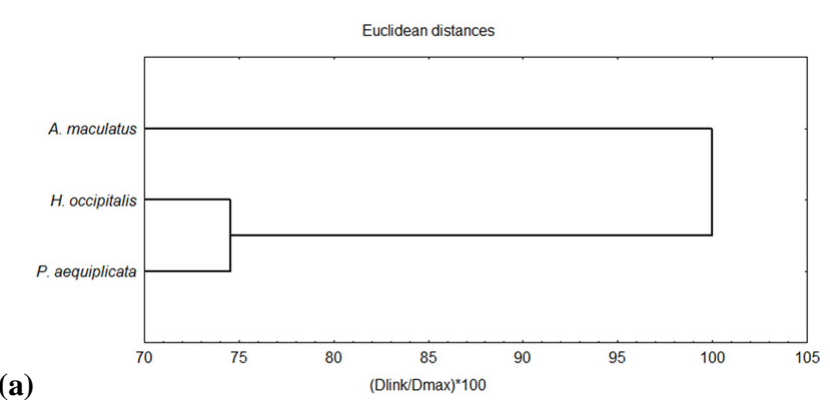

(a)

Figure 1. UPGMA dendrograms (standardized to 100\%) showing dissimilarity between host-anuran species in terms of their helminth communities (a), and among helminth species in terms of their associations with the three studied anuran species (b).

A UPGMA dendrogram showed that the two Ranidae clustered together in terms of helminth species parasitizing them, with Amietophrynus maculatus being substantially different (Fig. 1a). A same type of cluster analysis revealed three helminth clusters in terms of their association with anurans (Fig. 1b): (i) a cluster formed by Rhabdias, Mehraorchis, and Davainea, (ii) Oxyuris and Eurytrema; (iii) Polystoma and Raillietina.

The frequency of occurrence of helminthes was strongly uneven among tracts of the gastrointestinal system, either pooling the three anuran species $\left(\chi^{2}=1268.63, d f=3\right.$, $P<0.0001$ ) or considering them separately (A. maculatus: $\chi^{2}=1067.81, \quad d f=3, \quad P<0.0001 ; \quad H$. occipitalis: $\chi^{2}=125.63, d f=3, P<0.0001 ;$. aequiplicata: $\chi^{2}=83.00$, $d f=3, P<0.0001)$. In all the anurans, the esophagus harbored the least number of helminthes with only one species (Rhabdias bufonis) observed, and intestine was the favored sector of the anuran gastrointestinal system by all helminth species apart from Oxyuris sp. (Table 2). Rhabdias bufonis also occurred in other segments. The total number of helminthes extracted in the various segment indicate that their segment preference followed the order: (colon $=$ intestine) $>$ stomach $>$ esophagus. 
Table 2. Results of statistical analysis showing different species-specific preferences of helminth species for particular sectors of the gastrointestinal system of anuran species from Port Harcourt, Nigeria. When a same helminth species occurred in more than one anuran species, statistical analyses were performed on pooled numbers.

\begin{tabular}{lll}
\hline Helminth species & $\chi^{2}$ test $(d f=3)$, P-value & Sector Favored \\
\hline Rhabdias bufonis & $1331.27,<0.0001$ & Intestine \\
Oxyuris sp. & $2848.40,<0.0001$ & Colon \\
Eurytrema sp. & $198.54,<0.0001$ & Intestine \\
Mehraorchis sp. & $15,<0.0019$ & Intestine \\
Davainea sp. & $31.61,<0.0001$ & Intestine \\
Diphyllobothrium sp. & $63.00,<0.0001$ & Intestine \\
Aplectana acuminata & $70.59,<0.0001$ & Intestine \\
Polystoma sp. & Too small sample size for analysis & \\
Raillietina sp. & $15,<0.0019$ & Intestine \\
\hline
\end{tabular}

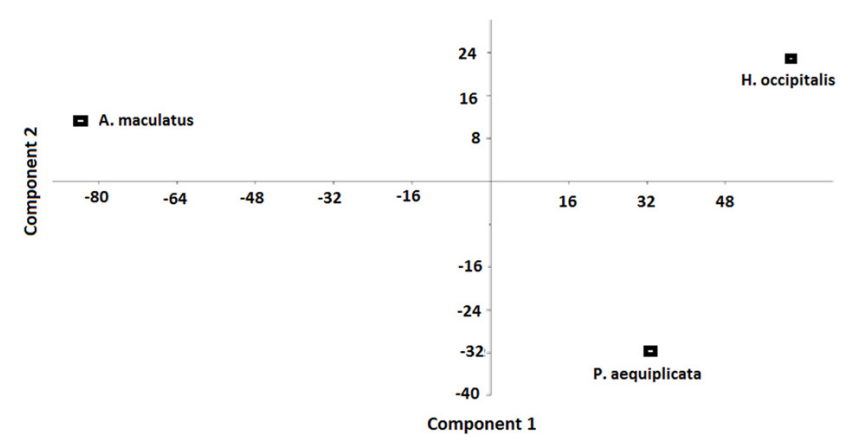

Figure 2. Scatterplot of a Principal Component Analysis classifying the three anuran species on the basis of the prevalence, intensity, and abundance of their gastrointestinal parasites.

\subsection{Helminth community structure}

Prevalence, intensity of infection, abundance and diversity for each helminth species in each of the three hosts are shown in Table 3. Amietophrynus maculatus showed more richness and diversity of helminth communities, having six helminth species, than $H$. occipitalis and $P$. aequiplicata. Combining prevalence, intensity, and abundance of parasites into a PCA (eigenvalues: component $1=6175.09$ with $88.14 \%$ of variance explained; component $2=830.63$ with $11.86 \%$ of variance explained), it resulted that each of the three anuran species was very different and spaced apart into the multivariate space (Fig. 2).

Niche overlaps between helminth species in the use of four gastrointestinal system sectors ranged $0.083-1$ in $A$. maculatus $(x=0.622$; variance $=0.145), 0.027-0.973$ in $H$. occipitalis $(x=0.495$; variance $=0.231)$, and $0.032-0.997$ in $P$. aequiplicata $(x=0.585$; variance $=0.217)$. Helminth communities were randomly organized in A. maculatus according to RA3 (mean of simulated indices $=0.350$; variance of simulated indices $=0.0089 ; P_{\text {obs } \leq \exp }=0.984$ ) and RA2 (mean of simulated indices $=0.621$; variance of sim- ulated indices $\left.=0.0087 ; \quad P_{\text {obs } \leq \exp }=0.506\right)$. Also in $H$. occipitalis there was no evidence of structured community of helminthes according to both randomization algorithms (RA3: mean of simulated indices $=0.348$; variance of simulated indices $=0.023 ; P_{\mathrm{obs} \leq \exp }=0.849 ; \mathrm{RA} 2$ : mean of simulated indices $=0.595$; variance of simulated indices $\left.=0.020 ; \quad P_{\text {obs } \leq \exp }=0.259\right)$. No community structure was also found in $P$. aequiplicata with both RA3 (mean of simulated indices $=0.326$; variance of simulated indices $=0.015 ; P_{\mathrm{obs} \leq \exp }=0.954$ ) and RA2 (mean of simulated indices $=0.639$; variance of simulated indices $=0.017$; $\left.P_{\text {obs } \leq \exp }=0.354\right)$.

\subsection{Anuran dietary habits}

All anuran species were insectophagous (Coleoptera were particularly frequently eaten) with Gastropoda being also commonly consumed (Table 4). Few plant parts were also found in anuran guts, but these were certainly ingested secondarily by them as all amphibians are strictly carnivorous. All species appeared clearly generalists in habits: excluding plant remains, a total of 10 different prey type categories were found in A. maculatus, and 9 prey types in each of the two Ranidae.

In terms of percentage of occurrence of food items, there were high niche overlaps values in all pairwise combinations (A. maculatus versus $H$. occipitalis $=0.796 ; A$. maculatus versus $P$. aequiplicata $=0.871 ; P$. aequiplicata versus $H$. occipitalis $=0.906 ; x=0.858$; variance $=0.003$ ), with no evidence of food niche partitioning using both RA3 (mean of simulated indices $=0.467$; variance of simulated indices $=0.008 ; P_{\mathrm{obs} \leq \exp }=0.999$ ) and RA2 (mean of simulated indices $=0.710$; variance of simulated indices $=0.005$; $P_{\text {obs } \leq \text { exp }}=0.992$ ).

Also in terms of percentage of abundance of food items, the results were not substantially different. Indeed, there were high niche overlaps values in all pairwise combinations (A. maculatus versus $H$. occipitalis $=0.967 ;$ A. maculatus 
Table 3. Infection parameters of the helminthes parasitizing three anuran species from Port Harcourt, Nigeria. Symbols: $n=$ number of infected hosts. Exam $=$ number of examined hosts. $N=$ overall number of helminthes.

\begin{tabular}{|c|c|c|c|c|}
\hline Anuran species & Helminth species & $\begin{array}{l}\text { Prevalence } \\
n / \text { Exam } \\
\%\end{array}$ & $\begin{array}{l}\text { Intensity } \\
\text { Range } \\
\text { mean }\end{array}$ & $\begin{array}{l}\text { Abundance } \\
N \\
\text { mean }\end{array}$ \\
\hline \multicolumn{5}{|c|}{ Amietophrynus maculatus } \\
\hline & \multirow{2}{*}{ Rhabdias bufonis } & $98 / 116$ & $1-28$ & 1134 \\
\hline & & 84.5 & 11.6 & 11.7 \\
\hline & \multirow{2}{*}{ Oxyuris sp. } & $102 / 116$ & $1-24$ & 1024 \\
\hline & & 87.9 & 10.0 & 11.0 \\
\hline & \multirow[t]{2}{*}{ Davainea sp. } & $6 / 116$ & $1-4$ & 13 \\
\hline & & 5.2 & 2.2 & 2.2 \\
\hline & \multirow[t]{2}{*}{ Diphyllobothrium sp. } & $5 / 116$ & $1-5$ & 15 \\
\hline & & 4.3 & 3.0 & 3.0 \\
\hline & \multirow[t]{2}{*}{ Eurytrema sp. } & $20 / 116$ & $2-30$ & 262 \\
\hline & & 17.2 & 13.1 & 13.1 \\
\hline & \multirow{2}{*}{ Mehraorchis sp. } & $2 / 116$ & $2-3$ & 05 \\
\hline & & 1.7 & 2.5 & 2.5 \\
\hline \multicolumn{5}{|c|}{ Hoplobatrachus occipitalis } \\
\hline & \multirow[t]{2}{*}{ Aplectana acuminata } & $8 / 9$ & $1-5$ & 21 \\
\hline & & 88.9 & 2.6 & 2.6 \\
\hline & \multirow[t]{2}{*}{ Oxyuris sp. } & $9 / 9$ & $9-20$ & 109 \\
\hline & & 100.0 & 12.1 & 12.1 \\
\hline & \multirow[t]{2}{*}{ Diphyllobothrium sp. } & $3 / 9$ & $1-3$ & 06 \\
\hline & & 33.3 & 2.0 & 2.0 \\
\hline & \multirow[t]{2}{*}{ Eurytrema sp. } & $9 / 9$ & $5-22$ & 104 \\
\hline & & 100.0 & 11.6 & 11.6 \\
\hline \multicolumn{5}{|c|}{ Ptychadena aequiplicata } \\
\hline & \multirow{2}{*}{ Aplectana acuminata } & $11 / 15$ & $1-5$ & 28 \\
\hline & & 73.3 & 2.6 & 2.6 \\
\hline & \multirow[t]{2}{*}{ Oxyuris sp. } & $13 / 15$ & $2-10$ & 64 \\
\hline & & 86.7 & 4.9 & 4.9 \\
\hline & \multirow[t]{2}{*}{ Raillietina sp. } & $2 / 15$ & $2-3$ & 05 \\
\hline & & 13.3 & 2.5 & 2.5 \\
\hline & \multirow[t]{2}{*}{ Eurytrema sp. } & $7 / 15$ & $3-21$ & 71 \\
\hline & & 46.7 & 10.1 & 10.1 \\
\hline & \multirow[t]{2}{*}{ Polystoma sp. } & $1 / 15$ & $0-1$ & 01 \\
\hline & & 6.7 & 1.0 & 1.0 \\
\hline
\end{tabular}

versus $P$. aequiplicata $=0.953 ; P$. aequiplicata versus $H$. occipitalis $=0.990 ; x=0.970$; variance $=0.251$ ), with again no evidence of food niche partitioning using both RA3 (mean of simulated indices $=0.251$; variance of simulated indices $=0.018 ; P_{\mathrm{obs} \leq \mathrm{exp}}=1.00$ ) and RA2 (mean of simulated indices $=0.709$; variance of simulated indices $=0.005$; $\left.P_{\text {obs } \leq \text { exp }}=1.00\right)$. Hence, we conclude that the three anuran species were substantially similar in terms of food composition, with no evidence of any interspecific competition for food among them.

\section{Discussion}

To begin with, we should stress that our samples were small for two of the three species (H. occipitalis and $P$. aequiplicata), and this fact may have somewhat influenced the results. This potential shortcoming aside, our study has nonetheless revealed some clear patterns concerning the communities of gastrointestinal parasites of the three studied anurans. Firstly, our study clearly showed that the helminth communities were quite depauperate in all the three species, with 4 to 6 species being detected in each host species. In this regard, our data perfectly agree with earlier studies 
Table 4. Diet descriptors of the three anurans from Port Harcourt, Nigeria. Symbols: $T=$ total number of prey items; $\% P=$ percentage of occurrence; $\% N=$ percentage of abundance.

\begin{tabular}{|c|c|c|c|c|c|c|c|c|c|}
\hline \multirow[t]{2}{*}{ Prey type } & \multicolumn{3}{|c|}{ A. maculatus } & \multicolumn{3}{|c|}{ H. occipitalis } & \multicolumn{3}{|c|}{ P. aequiplicata } \\
\hline & $T$ & $\% P$ & $\% N$ & $T$ & $\% P$ & $\% N$ & $T$ & $\% P$ & $\% N$ \\
\hline Coleoptera & 210 & 86.2 & 76.4 & 53 & 77.8 & 52.5 & 39 & 73.3 & 46.4 \\
\hline Lepidoptera & 03 & 1.7 & 1.1 & 03 & 22.2 & 3.0 & 02 & 6.7 & 2.4 \\
\hline Diptera & 04 & 2.6 & 1.5 & 02 & 22.2 & 2.0 & 03 & 6.7 & 3.6 \\
\hline Orthoptera & 04 & 3.5 & 1.5 & 03 & 33.3 & 3.0 & 04 & 26.7 & 4.8 \\
\hline Hymenoptera & 03 & 0.9 & 1.1 & 03 & 33.3 & 3.0 & 04 & 26.7 & 4.8 \\
\hline Isoptera & 01 & 0.9 & 0.4 & 02 & 11.1 & 2.0 & 04 & 20.0 & 4.8 \\
\hline Unidentified insects & 20 & 94.8 & 7.3 & 17 & 100.0 & 16.8 & 13 & 66.7 & 15.5 \\
\hline Acarina & 02 & 0.9 & 0.7 & - & - & - & 03 & 20.0 & 3.6 \\
\hline Miriapoda & 05 & 2.9 & 1.8 & 03 & 22.2 & 3.0 & - & - & - \\
\hline Gastropoda & 16 & 13.8 & 5.8 & 11 & 100.0 & 10.9 & 07 & 33.3 & 8.3 \\
\hline Plant parts & 07 & 6.0 & 2.6 & 04 & 33.3 & 3.8 & 05 & 33.3 & 6.0 \\
\hline
\end{tabular}

indicating that amphibian parasite communities are typically in the proximity to the isolationist extremity of the continuum (Aho, 1990). Also, null model analyses revealed that the helminth communities were not structured by niche resource partitioning in any of the anuran hosts. Hence, our data fit well with the idea that parasite communities form unstructured assemblages with little resource limitation and competitive influence (Rohde, 1991; Gotelli and Rohde, 2002). This pattern is also consistent with the theoretical predictions of the isolationist model for parasite communities. Overall, Afrotropical anurans conform with both temperate and Neotropical amphibians in terms of the general characteristics of their parasite communities.

The helminth communities found in the three anurans examined here differed slightly: three nematodes were recovered from A. maculatus, while two were recovered from both H. occipitalis and P. aequiplicata. Oxyuris sp. was common to all three anurans. Although this latter is primarily a mammal parasite, it has already been recorded as a parasite of amphibians elsewhere (e.g., Lehmann, 1960). Aplectana acuminata occurred in $H$. occipitalis and $P$. aequiplicata, while Rhabdias bufonis occurred only in A. maculatus. Of the cestodes, Diphyllobothrium sp. was common to A. maculatus and $H$. occipitalis. The trematode, E. pancreaticum occurred in all three hosts. The only monogenean recovered was from a $P$. aequiplicata specimen. No single community included all species locally available.

Our data revealed that, in terms of helminth community composition (presence/absence of the various parasites), there was an higher similarity between the two Ranidae than between each of the Ranidae and the only Bufonidae studied here. It is likely that this higher similarity may depend on the more similar general ecological habits of the two Ranidae (semi-aquatic) whereas the Bufonidae is terrestrial. An habitat effect on the abundance and richness of helminth parasites was also reported in earlier studies (e.g., McKenzie, 2007). However, when prevalence, intensity, and abundance of parasites are combined into a multivariate analysis, each anuran species was clearly spaced apart from the others, thus revealing considerable species-specific differences in terms of their parasite communities. We tentatively attribute these differences to microhabitat differences between the anuran species. For instance, $P$. aequiplicata tends to be more forest-linked than $H$. occipitalis, which is found also in open grassland ponds (Rödel, 2000; Akani et al., 2005).

Our diet data of the three anurans showed a generalist trophic spectrum for all species, with insects (especially coleopterans) and gastropods being important food items. Dietary generalism of the host has been predicted to be an ecological correlate of the isolationist structure of parasite communities (Poulin and Luque, 2003), and also in this regard our study fits well with theoretical expectations. It is likely that prey availability around the habitat of anurans was very important in regulating the food items, and that anurans ate all moving objects in their sight range that they can ingest (e.g., Toshiaki and Masafumi, 2001). However, it is noteworthy in our study that the overall dietary spectrum was similar among anuran species (as testified by the high niche overlap values observed), despite we included in the analyses anuran species with very different habitat and life-style characteristics. For instance, A. maculatus is strictly terrestrial, whereas the other two species are aquatic (Rödel, 2000), and they also differ locally in terms of microhabitat characteristics at most sites (e.g., Akani et al., 2005). In addition, our anuran species paralleled their helminth communities in that they did not compete interspecifically for food, as clearly shown by our null model analyses with both RA 2 and RA 3 algorithms. Also in this case, lack of interspecific competition for food is expectable among sympatric predators with generalist and opportunistic dietary habits (Pianka, 1986). 
Price (1990) stated that predation was an integral part of transmission in many animal parasite systems. In our study case, the three anurans were clearly indiscriminate, unspecialized predators of invertebrate organisms. This is widely in agreement with previous studies on anurans, and, because of this indiscriminated predatory activity, the degree of specificity of helminth parasites to particular species of hosts should be fairly low (Prudhoe and Bray, 1982). However, the nematodes found in this study are monoxenous and do not require an intermediate host, as infection is by skin penetration or egg ingestion, thus diet being unimportant in their case. Diet is however important to trematodes and cestodes (Anderson, 2000). In the case of nematodes, habitat should be of course important in the transmission. Considering that (i) primarily mammalian (and also human) parasites are common in the studied anurans, and that (ii) in part of the study areas there was an intense human activity (including the use of these ponds also as latrines), it is possible that this might have influenced the probability of transmission of these parasites to anuran hosts. Further researches are needed in order to confirm this hypothesis.

Acknowledgements. We are very grateful to the following people who helped us in different ways till the completion of the work: Alex Moore (Chief Technologists, Medical Laboratory Department, RSUST), Bob Manuel (Chief Technologist; Chemistry Department, RSUST). LL was supported during the preparation of this paper by research funds from Eni (years 2007-2008-2009). Two anonymous referees significantly improved an early draft of this manuscript. All individual anurans were sacrificed humanely following authorization by appropriate governmental authorizations.

Edited by: F. I. Pugnaire

Reviewed by: two anonymous referees

\section{References}

Aho, J. M.: Helminth communities of amphibians and reptiles: comparative approaches to understanding the patterns and processes, in: Parasite communities: patterns and processes, edited by: Esch, G. W., Bush, A. O., and Aho, J. M., Chapman and Hall, New York, 157-195, 1990.

Akani, G. C., Politano, E., and Luiselli, L.: Amphibians recorded in forest swamp areas of the River Niger Delta (southeastern Nigeria), and the effects of habitat alteration from oil industry development on species richness and diversity, Applied Herpetology, 2, 1-22, 2005.

Aisien, S. O., Ajakaiye, F. B., and Braimoh, K.: Helminth parasites of anurans from the savannah-mosaic zone of south-western Nigeria, Acta Parasitol., 48, 47-54, 2003.

Anderson, R. C.: Nematode Parasites of Vertebrates: Their Development and Transmission, 2nd Edn., CAB International, Wallingford, Oxon, UK, 650 pp., 2000.

Anonymous: Guidelines for Euthanasia of Nondomestic Animals, American Association of Zoo Veterinarians, New York, 2006.

Anosike, J. C. and Keke, I. R.: A survey of gastrointestinal helminthes of frog (Dicroglossus occipitalis) in south eastern
Nigeria, African Journal of Applied Zoology and Environmental Biology, 4, 47-49, 2002.

Anyacho, O. A.: Survey of helminth parasites of a common African toad Bufo regularis around University of Port Harcourt, Choba, Rivers State, B.Sc. Thesis, Department of Zoology, University of Port Harcourt, 32 pp., 1997.

Baker, M. R.: Synopsis of the Nematoda parasitic in amphibians and reptiles, Memorial University of Newfoundland, Occasional Papers in Biology, 11, 1-325, 1987.

Barton, D. P.: Ecology of helminth communities in tropical Australian amphibians, International Journal for Parasitology, 29, 921-926, 1999.

Bolek, M. G. and Coggins, J. R.: Seasonal occurrence and community structure of helminth parasites in green frogs, Rana clamitans melanota, from southeastern Wisconsin, U.S.A., Comp. Parasitol., 68, 164-172, 2001.

Brooks, D. R., Léon-Régagnon, V., McLennan, D. A., and Zelmer, D.: Ecological fitting as a determinant of the community structure of platyhelminth parasites of anurans, Ecology, 87, S76S85, 2006.

Bursey, C. R., Goldberg, S. R., and Parmalee, J. R.: Gastrointestinal helminthes of 51 species of anurans from Reserva Cuzco, Amazónico, Peru, Comp. Parasitol., 68, 21-35, 2001.

Bush, A. O., Lafferty, K. D., Lotz, J. M., and Shostak, A. W.: Parasitology meets ecology on its own terms: Margolis et al. revisited, J. Parasitol., 83, 575-583, 1997.

Esch, G. W., Bush, A. O., and Aho, J. M.: Parasite Communities: Patterns and Processes, Chapman and Hall, London, 1990.

Fowler, J. and Cohen, L. (Eds.): Practical statistics for field biology, 4th Edn., John Willey and Sons, Chichester, England, 1994.

Friggens, M. H. and Brown, J. H.: Niche partitioning in the cestode communities of two elasmobranches, Oikos, 108, 76-84, 2005.

Goldberg, S. R. and Bursey, C. R.: Helminthes of two frogs, Lithobates taylori and Lithobates vaillanti (Ranidae), from Costa Rica, Caribb. J. Sci., 43, 65-72, 2007.

Gotelli, N. J. and Graves, G. C.: Null models in ecology, Smithsonian Institution Press, Washington D.C., 1996.

Gotelli, N. J. and Rohde, K.: Co-occurrence of ectoparasites of marine fishes: a null model analysis, Ecol. Lett., 5, 86-94, 2002.

Guidelli, G. M., Isaac, A., Takemoto, R. M., and Pavanelli, G. C.: Endoparasite infracommunities of Hemisorubim platyrhynchos (Valenciennes, 1840) (Pisces: Pimeodidae) of Baia River, Upper Paran River floodplain, Brazil: specific composition and ecological aspects, Brazilian Journal of Biology, 63, 1-14, 2003.

Hamann, M. I., González, C. E., and Kehr, A. I.: Helminth community structure of the oven frog Leptodactylus latinasus (Anura, Leptodactylidae) from Corrientes, Argentina, Acta Parasitol., 51, 294-299, 2006.

Holmes, J. C. and Price, P. W.: Communities of parasites, in: Community Ecology: Pattern and Process, edited by: Anderson, D. J. and Kikkawa, J., Blackwell Scientific, Oxford, 187-213, 1986.

Lawlor, L. R.: Structure and stability in natural and randomly constructed competitive communities, Am. Nat., 116, 394-408, 1980.

Lehmann, D. L.: Some parasites of central California amphibians, J. Parasitol., 46, 1-10, 1960.

Luiselli, L.: Resource partitioning and interspecific competition in snakes: the search for general geographical and guild patterns, Oikos, 114, 193-211, 2006. 
Luiselli, L.: Do lizard communities partition the trophic niche? A worldwide meta-analysis using null models, Oikos, 117, 321330, 2008.

Marcogliese, D. J.: Pursuing parasites up the food chain: implications of food web structure and function on parasite communities in aquatic systems, Acta Parasitol., 46, 82-93, 2001.

McAllister, C. T., Bursey, C. R., and Freed, P. S.: Helminth parasites of selected Amphibians and Reptiles from the Republic of Ecuador, Comp. Parasitol., 77, 52-66, 2010.

McKenzie, V. J.: Human landuse and patterns of parasitism in tropical amphibian hosts, Biol. Conserv., 137, 103-116, 2007.

Muzzall, P. M., Gillilland III, M.G., Summeruch, C. S., and Mehne, C. J.: Helminth communities of green frogs Rana clamitans Latreille, from southwestern Michigan, J. Parasitol., 87, 962-968, 2001.

Pianka, E. R.: Ecology and Natural History of Desert Lizards, Princeton University Press, Princeton, 1986.

Poulin, R.: Interactions between species and the structure of helminth communities, Parasitology, 122, S3-S11, 2001.

Poulin, R. and Luque, J. L.: A general test of the interactiveisolationist continuum in gastrointestinal parasite communities of fish, International Journal for Parasitology, 33, 1623-1630, 2003.
Price, P. W.: Host populations as resources defining parasite community organization, in: Parasite communities: patterns and processes, edited by: Esch, G. W., Bush, A. O., and Aho, J. M., Chapman and Hall, New York, 20-40, 1990.

Prudhoe, S. and Bray, R. A.: Platyhelminth parasites of the Amphibia. British Museum (Natural History), Oxford University Press, London, 1-30, 1982.

Rödel, M.-O.: Herpetofauna of West Africa, Vol. 1, Amphibians of the West African savanna. Edition Chimaira, Frankfurt am Main, 332 pp., 2000.

Rohde, K.: Intra- and interspecific interactions in low density populations in resource-rich habitats, Oikos, 60, 91-104, 1991.

Sneath, P. H. and Sokal, R. R.: Numerical Taxonomy, 1st Edn., Freeman and Co., San Francisco, 1-50, 1973.

Sousa, W. P.: Patterns and processes in communities of helminth parasites, Trends Ecol. Evol., 9, 52-57, 1994.

Toshiaki, H. and Masafumi, M.: Food habits of an endangered Japanese frog, Rana porosa brevipoda, Ecol. Res., 16, 737-743, 2001.

Verma, A. K. and Singh, G.: A quantitative analysis of gastrointestinal helminthes (Trematoda: Digenea) infection in ranid frogs in Jammu, Zoos' Print Journal, 15, 233-238, 2000.

Zar, J. H.: Biostatistical analyses, 2nd Edn., Prentice-Hall, Inc., New Jersey, 186 pp., 1984. 